\title{
Do nutritional behaviors depend on biological sex and cultural gender?
}

\author{
Małgorzata Grzymisławska ${ }^{1, A-F}$, Elżbieta Alicja Puch ${ }^{2, A-F}$, Agnieszka Zawada ${ }^{2, B, D, F}$, Marian Grzymisławski ${ }^{2, A, C, E, F}$ \\ ${ }^{1}$ Department of Anatomy, Poznan University of Medical Sciences, Poland \\ ${ }^{2}$ Internal and Metabolic Diseases and Dietetics Department, Poznan University of Medical Sciences, Poland \\ A - research concept and design; $\mathrm{B}$ - collection and/or assembly of data; $\mathrm{C}$ - data analysis and interpretation; \\ $D$ - writing the article; $E$ - critical revision of the article; $F$ - final approval of the article
}

\author{
Address for correspondence \\ Elizbieta Alicja Puch \\ E-mail:apuch@ump.edu.pl \\ Funding sources \\ None declared

\section{Conflict of interest} \\ None declared

\section{Acknowledgements} \\ The authors are grateful to both of the anonymous \\ reviewers for their comments and important \\ remarks about the manuscript.
}

Received on August 30, 2016

Reviewed on September 21, 2016

Accepted on August 18, 2019

Published online on February 4, 2020

\begin{abstract}
Conventional knowledge, resulting from observations and experience, maintains the conviction that there are gender differences in the acquisition, preparation and consumption of food. This review shows differences between the sexes in eating behavior, food choice and nutritional strategy which were conditioned by evolution and by intra-individual (biological or psychological) and extra-individual (socioeconomic and cultural) factors. Women manifest a more pronounced trust in healthy nutrition, greater engagement in controlling body weight, a higher tendency to eat in a group and in stressful situations, and they frequently experience frustration due to their own nutritional behaviors, which reflects higher social pressure and their attempts to reduce eating-related pleasure. On the other hand, men prefer fatty meals with a strong taste, and are directed mainly by the pleasure of consumption; they more frequently furtively eat sweet foods while watching television, use more dietary supplements and more frequently visit fast food restaurants. Nutritional behavior, styles of nutrition, dietary profiles, approach to nourishment, approach to the place of meal consumption, and the sources of nutritional knowledge all demonstrate associations with gender. Reciprocal interactions between gender and diet are conditioned by physiological, psychological and sociocultural factors. This system of reciprocal interactions includes feedback: biological sex and cultural gender shape one's diet and, reciprocally, one's diet affects the deepening or flattening of gender differences. The analysis of reciprocally interacting factors entangled in the formation of a nutritional model may also represent an important element of pro-health prophylaxis and should be used in medical and dietary practice. Males in particular should be informed and educated about health-promoting diets.
\end{abstract}

Key words: eating habits, food intake, nutritional strategy, female subjects, male subjects

Cite as

Grzymisławska M, Puch EA, Zawada A, Grzymisławski M.

Do nutritional behaviors depend on biological sex and cultural gender? Adv Clin Exp Med. 2020;29(1):165-172. doi:10.17219/acem/111817

DOI

10.17219/acem/111817

\section{Copyright}

Copyright by Author(s)

This is an article distributed under the terms of the

Creative Commons Attribution 3.0 Unported (CC BY 3.0)

(https://creativecommons.org/licenses/by/3.0/) 


\section{Introduction}

Humans need energy to expend on physiological processes and physical activity. The energetic requirements are covered by supplying the human body with an appropriate amount of qualitatively adequate food, containing suitable proportions of specific nutritional components. Changes in metabolic requirements and energy expenditure, and, consequently dietary changes, have played a very important role in the process of hominids' evolution, especially when it comes to the development of the large human brain. ${ }^{1}$ The manner of nutrition should satisfy not only the energetic requirements of the body, but also normal psychophysical development and maintenance of good health and well-being. Human nutritional behaviors depend on individual (biological and psychological) and external (geophysical, socioeconomic and cultural) factors. ${ }^{2}$

Food choice is determined by biological variables, directed at satisfying physiological needs (first of all at appeasing hunger) - by compensating for a deficit in nutritional components until satiation is reached - and at satisfying needs linked to specific sensations of taste, smell and sight, which shape our nutritional habits. In turn, psychological factors, like stress level, emotional excitation and mood influence the manner in which we satisfy our appetites through the motivation to ingest the food, as well as influencing its quantity and quality. The geophysical factors which influence diet selection include the availability of specific food types, determined by natural conditions - the local topography, soil, climate, and the degree of development in transport and trade. The socioeconomic factors which shape our manner of nutrition include socioeconomic status, educational level, occupation, income, family status, and nutritional education, while tradition, national and regional culinary inheritance, beliefs, religious commands or prohibitions, and culinary culture are classified as cultural factors. ${ }^{3,4}$ The manner in which human alimentary needs are satisfied varies in time (historical aspect) and in space (geographical aspect). The key changes over time were connected with evolution from a nomadic lifestyle, with hunting and gathering as the means of acquiring food, to a settled way of life in the Neolithic age, which is associated with animal husbandry and agriculture. Spatial variability in satisfying alimentary needs can be illustrated by specific diets (e.g., Scandinavian or Mediterranean) or by national and regional cuisines, which differ in culinary art and the manner in which dishes are served, as well as in the principles governing their consumption. ${ }^{2,3}$

Popular knowledge, resulting from observation and experience, includes a conviction that there are gender differences in the acquisition, preparation and consumption of food. By pre-Neolithic times, these gender differences were noted: women played the role of gatherers while men hunted. Among contemporary hunter-gatherers - for example, the Hadza population in north-central
Tanzania - gender differences can be found in the frequency of consuming different food types. Hadza women spend less time foraging than men and are able to eat far more frequently, while the men eat a higher quality diet than the women. ${ }^{5}$ Perhaps modern men inherited from hunters their higher tendency to consume high-energy and high-fat foods. Women, on the other hand, inherited from their ancestresses a preference for carbohydrates and, at the same time, being under constant social pressure, they pay more attention to maintaining a healthy body weight, therefore following weight-loss diets more often than men.

The multitude of the abovementioned factors, shaping the manner of satisfying nutritional needs, provides the basis for formulating a thesis on the differences between women and men and for distinguishing male and female nutritional strategies.

The aim of this review of current scientific reports is to attempt to provide an answer to the question of whether - and if so, why - there are gender differences in nutritional behaviors.

\section{Cultural and biological factors affecting food habits and the human body}

The concept of a biological sex, based on anatomical, physiological and morphological traits, differentiates human beings into men and women, while the terms gender or cultural sex is related to the characteristics, roles, behaviors, activities, and attributes that society, culture, religion and tradition define as masculine or feminine. ${ }^{6}$

Scientific studies on the gender differentiation of diet, nutritional styles and any behaviors related to the satisfaction of alimentary needs - particularly in the context of genderism - do not have an exceptionally long history, but their results seem to prove gender-determined choices of nutritional strategy. ${ }^{7}$ The summary written by Beckmann indicates that the differentiation of nutritional styles between women and men reflects to a significant degree the model of organization in an individual's personal and family life, their education, the occupational and family functions they fulfill, the duties they perform, and the manner in which they spend their free time. Cultural norms, including patterns propagated by mass media, also represent a significant influential factor. Nutrition, as one of the most important vital functions of a human being, provides a broad area in which the typical traits of sexual dissimilarities, resulting from the abovementioned conditioning, are manifested. ${ }^{8}$

Biological sex, understood as the sum of morphofunctional differences, affects the choice of diet and of nutritional strategy. The larger energy demand in males is the result of genetically determined larger body height 
and weight in men. The modification of nutritional needs and their fulfillment in women during pregnancy is the result of hormonal changes taking place. In turn, the model of nourishment one adopts reciprocally affects the functioning and morphological traits of the human body. The percent of fat in body composition is higher on average in females and obesity is observed more frequently in women than in men. These findings reflect the significant gender metabolism of energetic substrates: female sex is characterized by a higher index of lipid synthesis (lipoproteins and unsaturated lipids) due to a pronounced effect of estrogens on the accumulation of lipids, while male sex manifests as a higher index of protein metabolism. However, advancing age in women is associated with a decrease in lipid biosynthesis, while advancing age in men promotes an increase in lipid synthesis over protein biosynthesis. ${ }^{9}$ In addition, higher concentrations on average of ghrelin (the hormone of hunger) are noted in women than in men, in whom the concentrations additionally continue to decrease with advancing age and falling testosterone level. ${ }^{10-12}$ In a similar way, the level of leptin (the hormone of satiety) - due to the action of estrogens - remains 2-3 times higher in women than in men, in whom testosterone reduces leptin synthesis. Treatment with testosterone decreases leptin concentration and, therefore, reduces the mass of lipids. ${ }^{13-15}$

The differences in the frequency of obesity in women and men may have more than a strictly biological background: on a global scale and in poor nations, the prevalence of female obesity is one and a half or even twice higher than the prevalence of male obesity, although in highly developed countries the proportions are reversed, e.g., in 19 European Union member countries in $2008,37-56 \%$ of women and as many as $69.3 \%$ of men were overweight or obese. ${ }^{16,17}$ In view of the estrogen hypothesis of obesity suggested by Grantham and Henneberg, ${ }^{18}$ the gender differences in the incidence of obesity in highly developed countries, which are unfavorable for men, most likely reflect the action of the significant amounts of estrogen drugs metabolism and xenoestrogens released to environment, as they disturb hormonal metabolism. These endocrinally active compounds penetrate the human body through direct consumption, like phytoestrogens, contained in soy products (particularly common in the USA) or through water and biological liquids, as in the case of di-2-ethyl-hexyl phthalate (DEHP), which is found in solvents of glues, varnishes and resins and in polyvinyl chloride - a common ingredient of plastic packaging. ${ }^{19}$

\section{Models of nutritional behavior}

The models of nutritional behavior differ between women and men both in the quantity and quality (composition) of diet, as well as in the frequency of meals, the time and place of consumption and in pro-health behaviors, which are linked to food habits and modifications of food habits.

A study on the mechanism of gender differences in food choice conducted on 19,298 students from 23 countries demonstrated that women more frequently than men give up high-fat foods, restrict their use of salt in the kitchen and more eagerly select meals with high content of dietary fiber, particularly fruits and vegetables. Gender differences in food choice - as much as $40 \%$ - can be explained by health beliefs: women have a more pronounced conviction regarding the benefits gained from eating healthy food and are more engaged in controlling their body weight. Finally, the distinct views of women and men related to dietary behaviors and health beliefs are responsible for $50 \%$ of gender-specific food choice. ${ }^{20}$

Differences are also observed in men's and women's approach to the consumption of sugary foods. Studies conducted by Grogan et al. on a group of 129 British students found significant gender differences in the amount and frequency of sweet snacks consumed. The study evaluated intentional and real attitudes and behaviors towards eating sugary snacks, the motivation to follow appropriate dietary recommendations and the inclination to take pleasure from consuming such snacks. Compared to men, women significantly more often declared an intention to avoid sweet foods, which probably reflected the fact that men's consumption of sugary foods was affected by less social pressure. Moreover, the females in the study presented a contradictory approach to consuming sweet snacks to a greater extent: in their minds, the attraction of taste prevailed over their awareness of the unfavorable effects of sugary snacks on their health. ${ }^{21}$ In addition, empirical studies on the sociocultural conditioning of consuming sugary foods, conducted on a representative group of 1,000 Polish adults, demonstrated that social situations promote their consumption differently for men and for women: women were found to eat sugary snacks more frequently during social meetings while men did so while watching television. ${ }^{22}$

Apart from the quantity and quality of meals consumed, the important elements shaping the models of nutritional behaviors also significantly depend on the frequency and place of their consumption. In a study group of 259 American college students, it was observed that twice as many women as men never visit fast food restaurants. In contrast, a higher percentage of men than women ( $74 \%$ vs $60 \%$ ) eat meals in this type of restaurant 1-3 times per week and in most cases, when selecting from the menu, they take into account the energy value of the food. Although a higher proportion of women (55\%) declared that "the nutritive value of food is important to me" ( $\mathrm{p}<0.0001)$, they are much less effective in choosing nutritional food than men. ${ }^{23}$

Using the three-factor Eating Behavior Scale (EBS), Horiguchi et al. analyzed the eating behaviors of young Japanese adults; they also detected significant gender 
differences. ${ }^{24}$ In a group of 404 men and 390 women under the age of 30 years, the consumption of meals by women was found to be more frequently stimulated by external factors ("extrinsic eating"):

- eating when others eat or

- eating when feeling irritated.

On the other hand, in the group of men the prevailing motivating factor was "a strong taste," promoting :

- selection of meals with a clear-cut taste and

- consumption of greasy foods.

There were no gender differences in "eating quickly":

- rate of eating meals and

- the habit of insufficiently chewing the food.

\section{Healthy eating}

According to an all-European sample survey $(14,331$ respondents), a normal or healthy diet should first of all contain more fruits and vegetables, but a detailed analysis demonstrated differences between individual countries as well as a variability depending on the age, educational level and gender of the examined individuals. Women more frequently than men indicated that a healthy diet should contain more vegetables or less fat and that the diet should be balanced, but the highest contradiction between women and men was related to fruit and vegetable consumption. ${ }^{25}$

According to a study of 309 Brazilian adult respondents, the main gender difference in healthy eating, and thus the choice of healthy food, consisted of different interpretations of healthiness as a motivation for food choices. The men preferred food that they believed maintains their health, while women focused on the nutritional value of food products. ${ }^{26}$

An analysis of the eating habits of 682 Polish university students showed that $53.4 \%$ of them evaluated their nutrition to be abnormal due to a lack of time $(63 \%)$, poor organization of classes (45.9\%), a lack of appetite (11.5\%), an attempt to lose weight (9.2\%), and financial problems (5.9\%). As with earlier research, this study showed that women report following the principles of proper nutrition, but no statistical significance could be demonstrated in this variable. ${ }^{27}$

The dietary behaviors of men are manifested in their use of various dietary supplements. According to Lieberman et al., ${ }^{28}$ they take supplements significantly more often and more numerously than women do (17.4 vs 8.6 ), a finding from their studies on 1,248 students of 5 American universities. Men used protein preparations and amino acids more often in order to improve their muscular strength and more frequently consumed drinks and gels designed for athletes and purported steroid analogues in order to increase energy, efficiency and resistance of the body. On the other hand, multivitamins and mineral supplements for improving overall health were used by women significantly more often (22.7 vs 31.9$)$. As a result, men spend twice as much money on dietary supplements per month than women do (USD 24 vs USD 12).

Moreover, men to a greater extent than women link a healthy lifestyle with the inclusion of regular physical activity in everyday duties rather than with the modification of their model of nutrition. ${ }^{29}$ Thus, physical activity may represent for them the first step toward altering nutritional behavior expressed as a reduced caloric intake and an improved nutritional quality of meals. Furthermore, individuals practicing sport to a greater extent care about their profile and attempt to balance their menu in respect to both macro- and microelements in order to gain better endurance results. Reduced concentrations of neuropeptides controlling the sensation of hunger (cocaine- and amphetamine-mediated transcript - CART) resulting from physical exercise may also significantly shape nutritional habits. ${ }^{30}$

A summary of numerous studies related to the selection and consumption of food by females in Western societies published by Arganini et al. indicates that they tend to select healthier food and are much more concerned than men with choosing appropriate food and nutritional behaviors which are important for maintaining good physical condition. ${ }^{31}$

Gender differences in changes to the perception of the importance of a well-balanced diet and its impact on health were studied in a Norwegian population. ${ }^{32}$ It was found that women are more aware of the relationship between diet and health, are more likely to change their views and more often implement a healthy, well-balanced diet than men. These gender differences result from greater health consciousness among women; consequently, they more often change their diet in relation to dietary recommendations and have more knowledge about health. Similarly, girls have a greater tendency to eat healthy food, such as vegetables, than boys, according to a study on 11-year-old Finnish children. ${ }^{33}$ Moreover, these girls had more of a preference for eating vegetables than boys 1 year after their parents intervened in order to encourage them to consume vegetables every day. The authors suggest that intervention aimed at increasing vegetable consumption among boys should consist of education that reduces their reluctance to eat vegetables and shows the benefits of eating them.

It seems that the gender differences in perception, inclinations and dietary barriers are already present in childhood and are reduced or deepened by the family. This is confirmed by numerous studies, including one on lowincome American families. ${ }^{34}$ It was found that the perception of the home environment in terms of nutritional factors, especially fruit and vegetable diet, held by children and their parents were similar. This similarity of parents' and children's perceptions of the home nutritional environment should be taken into account when designing intervention measures to change nutrition towards a wellbalanced diet, for example by reducing the volume of meals 
and increasing the number of them, and increasing children's consumption of fruit and vegetables.

According to Menozzi et al., in their study of 751 Italian students, women showed more rational behavior to a vegetable diet in light of the theory of planned behavior application. ${ }^{35}$ Females showed significantly greater perceived behavior control, attitudes toward behavior and subjective norms, and consequently greater intention to more frequently eating and serving vegetables than males. These results suggest that efforts to increase intention by targeting attitudes, subjective norms and perceived behavior control could have the effect of increasing the consumption of vegetables among the male population.

\section{Own eating habits and body weight}

Davy et al. demonstrated that the perception of one's own food habits differs significantly between women and men. ${ }^{36}$ Women much more frequently than men judged that they eat too many carbohydrates (59.7\% vs $41.9 \%$ ) and expressed the need to reduce this consumption in their diet more frequently than men did (46.4\% vs $27.6 \%$ ). Moreover, they noted more frequently than men the need to reduce the amount of fat in their diet (71.7\% vs $52.4 \%)$ and the need to reduce their body weight (57.4\% vs $28.6 \%$ ). Despite these gender differences, as many as $94.4 \%$ of all participants in the study agreed that one should consume more vegetables and fruits, and that a healthy diet which assures good health is a diversified diet. Following such a diet was reported by $66 \%$ of respondents, even if twice as many women (over 20\%) as men (over 10\%) simultaneously expressed a deep conviction of the need to reduce their body weight. ${ }^{36}$ Similar results had been obtained by Timperio et al., who confirmed that women are more engaged than men in maintaining correct body weight by avoiding body weight gain (30.2\% vs $23.3 \%$ ) and by weight loss attempts (22.2\% vs $12.6 \%){ }^{37}$

A significant factor affecting the analysis of one's own eating habits and adherence to dietary recommendations is the body weight of the individual. In multiple studies, individuals with overweight and obesity reported a higher motivation to observe dietary recommendations, irrespective of their gender. This was also confirmed by the positive correlation found between body mass index (BMI) and implementation of nutritional recommendation in both genders; however, women more frequently than men reduced consumption and, therefore, women more frequently than men were underweight ( $24.4 \%$ vs $15.5 \%){ }^{38}$

\section{Abnormal body weight and adjustment of food habits}

Markey and Markey proved that people who are dissatisfied with their body weight and who aimed to look leaner were more inclined to engage in pro-health behaviors and exhibited a higher tendency to engage in risky nutritional behaviors. On the other hand, a reciprocal relationship was detected between satisfaction with one's body weight and healthy and risky nutritional models. ${ }^{39}$

Sex/gender also significantly affects the results of treatment in obese individuals. A study by Presnell et al. aimed at analyzing differences in the behaviors of men and women during a program of obesity treatment. ${ }^{40}$ The investigators evaluated factors such as self-control of body weight, attacks of unrestrained appetite and symptoms of depression, which were found to be potential predictors of a loss in body weight. Men were found to manifest a much higher level of self-control in their aspiration for effective treatment only at the beginning of the therapy. On the other hand, women demonstrated a higher tendency to overeat and much more frequently manifested symptoms of depression. ${ }^{40}$

Statistically significant gender differences were demonstrated by Leblanc et al. in a group of 123 individuals subjected to a 12-week nutritional intervention (Mediterranean diet) based on the self-determination theory (SDT). ${ }^{41}$ In an analysis of changes to eating habits, nutritional behaviors, anthropometric data, and metabolic parameters, the group of men manifested a significantly more pronounced reduction than women in the consumption of fried red meat and an increase in the consumption of fruits, vegetables and dietary fiber. Moreover, the male population showed a reduction in the intake of polyunsaturated fatty acids in their diet. In both women and men, an improvement was noted in lipid panels (TC:HDL-C, TG and TG:HDL-C), but the changes were more accentuated in the group of men. The observations indicated that nutritional interventions based on personal motivation bring about more favorable long-term effects among men. ${ }^{41}$

\section{Eating behavior and social environment}

The effect of social environment on the differences observed in the nutritional behaviors of women and men are also significant: in a study by Lin et al., ${ }^{38}$ a reciprocal relationship was demonstrated between an individual's nutritional behaviors and social functioning. Eating habits and physical activity, aside from the support of family and friends, represented significant factors influencing the psychological sphere including the feeeling of social acceptance. On the other hand, the personal nutritional model was influenced by an individual's current body weight, fear of it increasing and their general emotional condition. The study also stressed the role of psychological and behavioral factors in implementing nutritional intervention programs and, in particular, programs for reducing body weight. The social pressure which is unfavorable for 
women and which promotes a slim figure results in more pronounced nutritional restrictions and less favorable emotional states for women. Nutritional restrictions frequently provide grounds for developing deficits in nutritive components, reflecting drastic dietary self-restraint and following an unbalanced diet. Moreover, in certain women, the restrictive diet accentuate emotional disturbances, which aggravate improper nutritional behaviors. Even if obesity is found in highly urbanized societies more frequently in men than in women, men encounter less pronounced social discrimination than women do, because body weight in women represents an important variable which affects the implementation of their ambitions and occupational plans. ${ }^{38}$

Ahmed et al. defined the effect of stress on nutritional behaviors. ${ }^{42}$ In a group of 407 students from Kuwait, stress was demonstrated to determine changes in nutritional behaviors. Among the groups of both women and men, stressful situations resulted in statistically more frequent consumption of high-calorie, high-fat meals and in an increased intake of high-calorie drinks. On the other hand, in the group of women, the clearly increased consumption was related to sweet snacks and coffee and tea. ${ }^{42}$

In their studies on the relationships between the level of stress and dietary restrictions and preferences, Habhab et al. showed that marginally stressed women preferred sweets and high-energy food, while less stressed women consumed more low-energy food. ${ }^{43}$ The experiment remains consistent with the results of a previously conducted study in which people on a low-carbohydrate diet showed a decrease in positive emotions and an increase in low moods, exhaustion and tiredness. ${ }^{44}$

In a study by Leblanc et al. ${ }^{45}$ on groups of 64 men and 59 women, gender differences were demonstrated in their nutritional habits and in their level of motivation towards nutrition. The male diet contained a higher overall energy value and a higher value per meal, with a higher percentage of energy in the daily ration originating from fats than from carbohydrates. The women had a better dietary profile than the men: a healthier diet, lower caloric density and a better metabolic profile. As compared to the men, the female nutritional model was dictated by their higher emotional sensitivity and higher value of Self-Determination Index (SDI). The value of this index showed a negative correlation with the energy content of their meals. ${ }^{45}$

\section{Sources of nutritional knowledge}

A significant effect on modification of dietetic behavior is exerted by the range of sources from which women and men draw information on nutrition. According to Davy et al., ${ }^{36}$ the sources of information on diet most frequently employed by respondents over the age of 25 years (irrespective of gender) were as follows: television (72\%), journals (58\%), newspapers (33\%), radio (18\%), family and/ or friends (17\%), books (14\%), the internet (13\%), a physician (12\%), work (4\%), and school (4\%). The analysis by gender indicated that women significantly more frequently than men took advantage of the knowledge transmitted by family and friends ( $58.0 \%$ vs $40.0 \%$ ), newspapers, magazines, and books (43.1\% vs 30.5\%). On the other hand, men searched for information on diet mainly in school. ${ }^{36}$ Similar results were obtained by Morse and Driskell ${ }^{23}$ among 259 American college students. In general, more women (60\%) than men (49\%) learned about nourishment from family and a significantly higher percentage of women than men drew their knowledge on nutrition from friends (39\% vs 25\%), from newspapers and from magazines (54\% vs $36 \%$ ). In turn, according to results obtained by Lieberman et al., ${ }^{28}$ there are also gender differences in finding information on dietary supplements. Family, healthcare providers and television constitute significantly more frequent sources of information for women, while men obtain their information more frequently from friends, trainers, instructors, newspapers and magazines, educational websites, or salesmen. The highest percentage (45.1\%) of men receive information on dietary supplements from the internet, while the highest percentage of women (43.3\%) get it from their families. ${ }^{28}$ Additional education, conducted among the male population in particular, as well as a solid and essentially correct manner of transmitting such information might provide an additional element of prohealth policy, leading to improved knowledge on correct nutritional habits. The effect of knowledge obtained from the popular media cannot be neglected as well.

\section{Summary and conclusions}

This review of scientific reports justifies the statement that nutritional behavior, styles of nutrition, dietary profile, approach to nourishment and to the place of consuming meals, and the sources of knowledge on nutrition demonstrate associations with gender. Half of the gender-related differences in food choice can be explained by nutritional behaviors and health convictions. Women demonstrate more trust in healthy nutrition and a greater engagement in controlling body weight, and they select healthier food than men do. Moreover, women manifest a higher tendency to eat in a group setting, including the consumption of snacks when other people eat, and in stressful situations. Besides, they choose the pleasure of tasting sugary foods over the consequences of their adverse effects on weight loss and overall health. On the other hand, men prefer fatty meals with strong flavors and they more frequently eat sugary snacks furtively while watching television. Men also more frequently than women use dietary supplements and visit fast food restaurants. Moreover, men more frequently than women practice regular physical activity and modify their diet in order to reduce their body weight and 
to improve their physical condition, whereas women more frequently experience frustration due to their own nutritional behaviors, which reflects higher social pressure and their attitude towards reducing eating-associated pleasure. On the other hand, in men, who are guided mainly by taste, the pleasure of consumption prevails.

The type and place of consuming food, any dietary challenges undertaken and fixed nutritional behaviors might represent an additional element of pro-health policy, leading to wider knowledge about proper eating habits despite the anatomical and physiological differences between genders. Likewise, the dissemination of knowledge about the nutritional strategies accepted by men and women, which differ in terms of the quantity and quality of food consumed, nutritional style and habits linked to the preparation and consumption of food as well as sociocultural factors (eg. education, professional and economic status, tradition, religion). The reciprocal effects of sex/gender (in the biological and cultural sense) on diet - and, more strictly, on the entirety of nutritional behaviors - and the reciprocal effect of diet on the psychophysical and cultural traits of gender remain conditioned by physiological and sociocultural factors. This system of reciprocal interactions creates a feedback loop: sex and gender exert an influence on diet and, reciprocally, diet affects the deepening or flattening of sex/gender differences (Fig. 1).

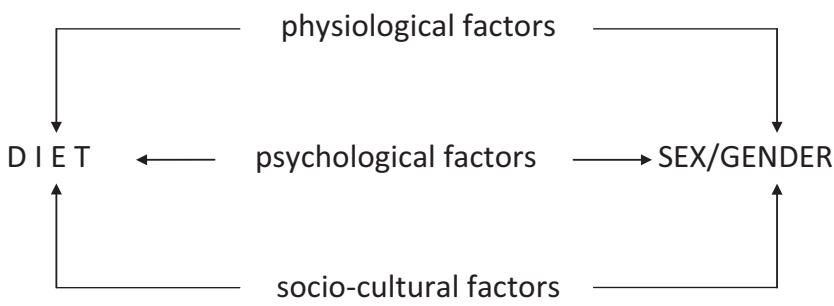

Fig. 1. Factors which modify sex/gender $\leftarrow \rightarrow$ dietary feedback

There is a clear need to design interventions to improve the health and wellbeing of populations by insisting on increasing the number of health-promoting dietary choices and discouraging food choices that adversely affect health. An analysis of reciprocally interacting factors entangled in the formation of a nutritional model may also represent an important element of pro-health prophylaxis and should be used in the nutritional recommendations suggested by physicians and dieticians. Both parents and children should be informed and educated about proper nutrition, a well-balanced diet and the resulting health benefits. Boys and adult men in particular should be subjected to nutritional education, as research has revealed gender differences which put them at a disadvantage.

\section{ORCID iDs}

Małgorzata Grzymisławska (D) https://orcid.org/0000-0002-1217-9867 Elżbieta Alicja Puch (1) https://orcid.org/0000-0002-9142-6108 Agnieszka Zawada (D) https://orcid.org/0000-0001-6995-090X Marian Grzymisławski (D) https://orcid.org/0000-0003-0868-354X

\section{References}

1. Leonard WR, Robertson ML. Nutritional requirements and human evolution: A bioenergetics model. Am J Hum Biol.1992;4(2):179-195. doi:10.1002/ajhb.1310040204

2. Counihan CM. Food and gender: Identity and power. In: Counihan CM, Kaplan SL, eds. Food in History and Culture. Series. Reading, UK: Harwood Academic Publishers, Tylor \& Francis e-Library; 2005:1-11. http://elibrary.kiu.ac.ug:8080/xmlui/bitstream/handle/1/853/ Food\%20and\%20Gender\%20Identity\%20and\%20Power. pdf?sequence=1\&isAllowed=y. Accessed June 15, 2016.

3. Turner BL, Thompson AL. Beyond the Paleolithic prescription: Incorporating diversity and flexibility in the study of human diet evolution. Nutr Rev. 2013;71(8):501-510.

4. Bellisle F. Why should we study human food intake behaviour? Nutr Metab Cardiovasc Dis. 2003;13(4):189-193.

5. Berbesque JC, Marlowe FW, Crittenden AN. Sex differences in Hadza eating frequency by food type. Am J Hum Biol. 2011;23(3):339-345.

6. Encyclopaedia Britannica, http://www.britannica.com/. Accessed June 15, 2016.

7. Blickhäuse $A$, von Bargen $\mathrm{H}$. Fit for gender mainstreaming. Berlin, Germany; 2007. www.fit-for-gender.org. Accessed June 15, 2016.

8. Beckmann G. Nutrition and gender. Summary of different specialist articles. http://www.fit-for-gender.org/toolbox/toolboxEN/Downloads/2.\%20Exercises/Englische_PDFsExercise/2.3\%20Gender\%20 in\%20Expert\%20Fields/2.3.6\%20(1).pdf. Accessed June 15, 2016.

9. Kochhar S, Jacobs DM, Ramadan Z, Berruex F, Fuerholz A, Fay LB. Probing gender-specific metabolism differences in humans by nuclear magnetic resonance-based metabonomics. Anal Biochem. 2006; 352(2):274-281.

10. Kozakowski J, Dudek P, Zgliczyński S. Serum ghrelin level in men is lower than in women and it decreases with age and with decline of serum testosterone level. Endokrynol Pol. 2004;55(4):414-420.

11. Makovey J, Naganathan V, Seibel M, Sambrook P. Gender differences in plasma ghrelin and its relations to body composition and bone: An opposite-sex twin study. Clin Endocrinol (Oxf). 2007;66(4):530-537.

12. Abu-Farha M, Mohammed Dehbi M, Noronha F, et al. Gender differences in ghrelin association with cardiometabolic risk factors in Arab population. Int J Endocrinol. 2014; Article ID 730472, http://dx.doi. org/10.1155/2014/730472. Accessed June 15, 2016.

13. Hellström L, Wahrenberg H, Hruska K, Reynisdottir S, Arner P. Mechanisms behind gender differences in circulating leptin levels. J Intern Med. 2000;247(4):457-462.

14. Rosenbaum M, Pietrobelli A, Vasselli JR, Heymsfield SB, Leibel RL. Sexual dimorphism in circulating leptin concentrations is not accounted for by differences in adipose tissue distribution. Int J Obes. 2001;25(9):1365-1371.

15. Dudek P, Zgliczyński S. In men testosterone therapy decreases serum leptin concentration and diminishes the fat mass. Endokrynol Pol. 2003;54(1):57-63.

16. World Health Organization. Obesity and overweight. WHO; 2015. http://www.who.int/mediacentre/facts. heets/fs311/en/. Accessed June 17, 2016.

17. Eurostat. Overweight and obesity - BMI statistics. Eurostat; 2016. http://ec.europa.eu/eurostat/statistics-explained/index.php/Overweight_and_obesity_-_BMI_statistics. Accessed June 17, 2016.

18. Grantham JP, Henneberg M. The estrogen hypothesis of obesity. PLoS One. 2014;9(6):e99776. eCollection 2014. Accessed June 17, 2016. doi:10.1371/journal.pone.0099776

19. Woźniak M, Murias M. Xenoestrogens: Substances disturbing function of hormonal system [in Polish]. Ginekol Pol. 2008;79(11):785-790.

20. Wardle J, Haase A, Steptoe A, Nillapun M, Jonwutiwes K, Bellisie F. Gender differences in food choice: The contribution of health beliefs and dieting. Ann Behav Med. 2004;27(2):107-116.

21. Grogan SC, Bell R, Conner M. Eating sweet snacks: Gender differences in attitudes and behavior. Appetite 1997;28(1):19-31.

22. Jeznach M, Jeżewska-Zychowicz M, Kosicka-Gębska M. Konsumpcja słodyczy i jej społeczno-kulturowe uwarunkowania. Probl Hig Epidemiol. 2011;92(4):806-809.

23. Morse KL, Driskell JA. Observed sex differences in fast-food consumption and nutrition self-assessments and beliefs of college students. Nutrition Research. 2009;29(3):173-179. 
24. Horiguchi M, Tanaka G, Ogasawara H, Maruyama R. Validation and gender-based comparison of the eating behavior scale for Japanese young adults. Psychology. 2014;5(19):2173-2179.

25. Margetts B, Martine JA, Saba A, Holm L, Kearney M. Definitions of "healthy" eating: A pan-EU survey of consumer attitudes to food, nutrition and health. Eur J Clin Nutr. 1997;51(2):23-29.

26. Missagia SV, de Oliveira SR, de Rezende DC. Food choice motives and healthy eating: Assessing gender differences. Paper presented at: XXXVI Encontro da ANPAD; September 22-26, 2016; Rio de Janeiro, Brazil. http://www.anpad.org.br/admin/pdf/2012_MKT922.pdf

27. Rasińska R. Nawyki żywieniowe studentów w zależności od płci. Now Lek. 2012;81(4):354-359.

28. Lieberman HR, Marriott BP, Williams C, et al. Patterns of dietary supplement use among college students. Clin Nutr. 2015;34:976-985. http://dx.doi.org/101016/j.clnu.2014.10.010.

29. Smee D, Pumpa K, Falchi M, Lithander F. The relationship between diet quality and falls risk, physical function and body composition in older adults. J Nutr Health Aging. 2015;19(10):1037-1042.

30. Shevchenko Y, Mamontova T, Baranova A, Vesnina L, Kaidashev I. Changes in lifestyle factors affect the levels of neuropeptides involved in control of eating behavior, insulin resistance and level of chronic systemic inflammation in young overweight persons [in Russian]. Georgian Med News. 2015;248:50-57.

31. Arganini C, Saba A, Comitato R, Virgili F, Turrini A. Gender differences in food choice and dietary intake in modern Western societies. In: Maddock J, ed. Public Health, Social and Behavioral Health. http:// cdn.intechopen.com/pdfs/36935.pdf. Accessed June 15, 2016.

32. Fagerli RA, Wandel M. Gender differences in opinions and practices with regard to a "healthy diet". Appetite. 1999;32(2):171-190.

33. Lehto E, Ray C, Haukkala A, Yngve A, Thorsdottir I, Roos E. Predicting gender differences in linking for vegetables and preference for a variety of vegetables among 11-year-old children. Appetite. 2015;95: 285-292.

34. Robinson-O'Brien R, Neumark-Sztainer D, Hannan PJ, Stat M, Burgess-Champoux T, Heines J. Fruits and vegetables at home: Child and parent perceptions. J Nutr Educ Behav. 2009;41(5):360-364.
35. Menozzi D, Sogari G, Mora C. Explaining vegetable consumption among young adults: An application of the theory of planned behaviour. Nutrients. 2015;7(9):7633-7650.

36. Davy SR, Benes BA, Driskell JA. Sex differences in dieting trends, eating habits, and nutrition beliefs of a group of Midwestern college students. J Am Diet Assoc. 2006;106(10):1673-1677.

37. Timperio A, Burns C, Cameron-Smith D, Crawford D. "Fattening" foods. Perceptions and misconceptions: A qualitative and quantitative exploration. Nutr Diet. 2003;60(4):230-238.

38. Lin KG, Cobiac L, Skrzypiec G. Gender differences in eating behavior and social self-concept among Malaysian University students. Mal J Nutr. 2002;8(1):75-98.

39. Markey CN, Markey PM. Relations between body image and dieting behaviors: An examination of gender differences. Sex Roles. 2005; 53(7-8):519-530.

40. Presnell K, Pells J, Stout A, Musante G. Sex differences in the relation of weight loss self-efficacy, binge eating, and depressive symptoms to weight loss success in a residential obesity treatment program. Eat Behav. 2008;9(2):170-180.

41. Leblanc V, Bégin C, Hudon AM, et al. Gender differences in the longterm effects of a nutritional intervention program promoting the Mediterranean diet: Changes in dietary intakes, eating behaviors, anthropometric and metabolic variables. Nutr J. 2014;13(107):1-19.

42. Ahmed F, Al-Radhwan L, Al-Azmi G, Al-Beajan M. Association between stress and dietary behaviors among undergraduate students in Kuwait: Gender differences. J Nutr Health Sci. 2014;1(1):1-8.

43. Habhab S, Sheldon JP, Loeb RC. The relationship between stress, dietary restraint, and food preferences in women. Appetite. 2009; 52(2):437-444.

44. Butki BD, Baumstark J, Driver S. Effects of a carbohydrate-restricted diet on affective responses to acute exercise among physically active participants. Percept Mot Skills. 2003;96(2):607-615.

45. Leblanc V, Bégin C, Corneau L, Dodin S, Lemieux S. Gender differences in dietary intakes: What is the contribution of motivational variables? J Hum Nutr Diet. 2015;28(1):37-46. 